\title{
Malarial parasitism and male competition for mates in the western fence lizard, Sceloporus occidentalis
}

\author{
J.J. Schall and M.D. Dearing \\ Department of Zoology, University of Vermont, Burlington, VT 05405, USA
}

\begin{abstract}
Summary. The effect of malarial parasitism on the ability of male western fence lizards, Sceloporus occidentalis, to compete for access to females was assessed experimentally. Pairs of male lizards, one infected with the malarial parasite, Plasmodium mexicanum, and the other not infected, were matched by size and color and placed in large seminatural outdoor enclosures along with an adult female lizard. Infected males displayed to females and to other males less often than did noninfected male lizards. Noninfected lizards were dominant in social interactions more often than malarious animals, based on duration and intensity of agonistic encounters toward the other male, and time spent with the female. Thus, malarial infection hinders the ability of male fence lizards to compete for mates.
\end{abstract}

Key words: Mate competition - Parasitism - Malaria Lizards - Sceloporus

An important, but often subtle, component of the lifetime reproductive success of a sexually reproducing animal is its ability to attract and court mates. In many species males compete for access to receptive females, and females may either simply accept the winner of these conflicts or actively select mates based on some indication of their biological quality. A burgeoning literature documents the intricate and sometimes unsuspected factors that can influence mating success (Bateson 1983; Blum and Blum 1979).

Most free-living animals are exploited by a variety of parasitic animals, plants, bacteria, and viruses that are often severely pathogenic. Intuition suggests that pathogenic parasites could play a significant role in mate acquisition by their hosts (Freeland 1976). Evidence for this proposal is scant, but intriguing. An extreme case is parasitic castration of hosts (Kuris 1974; Baudoin 1975). A less conspicuous example involves the alteration by a parasite of the dominance status of male host individuals (Freeland 1981; Hausfater and Watson 1976; Rau 1983). Females, in turn, may assortatively mate with parasite-free males, using phenotypic features as cues to male health (Hamilton and Zuk 1982; Ressel 1986). Despite these hints of the role of parasites in the mate competition/mate choice process, the precise way parasitic infection influences sexual selection is very poorly understood.

We examined the influence of malarial parasitism on

Offprint requests to: J.J. Schall the outcome of male-male interactions and female choice in the western fence lizard, Sceloporus occidentalis, in California, USA. The mating system of $S$. occidentalis is polygamous. Males interact agonistically toward other males and vigorously court females during the reproductive season. Their conspicuous stereotyped behaviors include bobbing, shaking, and display of brightly colored ventral color patches (Schall and Sarni 1987; Ressel 1986). At our study site approximately $25 \%$ of adult male fence lizards are infected with the malarial parasite, Plasmodium mexicanum (Schall 1983; Bromwich and Schall 1986). This parasite reduces the ability of the fence lizard to engage in intense activity; infected males also have smaller testes (Schall 1983; Schall et al. 1982). Perhaps as a result of these pathological effects of infection, malarious lizards are socially active less often than are noninfected animals (Schall and Sarni 1987). These results suggested to us that infected males may have difficulty in gaining access to females. We tested this hypothesis by staging standardized contests between infected and noninfected male fence lizards. To our knowledge, this provides the first demonstration of the impact of any parasite on competition for mates in a reptile.

\section{Methods}

The study area was the University of California Hopland Field Station, located in southern Mendocino County, California, USA. This tract of oak woodland has been described in detail elsewhere (Schall 1983; Bromwich and Schall 1986). Sceloporus occidentalis is common on rocks, logs, and fence rows. We collected lizards by noosing; each animal was individually marked by toe clipping and a number painted on its back with Liquid Paper. Blood taken from toe clips was used to make smears that were fixed in methanol and stained with Giemsa. Only one of us (JJS) viewed the slides under $900 \mathrm{X}$ to determine if the animal was infected with Plasmodium mexicanum, or two other blood parasites, Schellackia occidentalis (another protozoan), or a piroplasm (probably a virus) (Schall 1983; Telford 1984). Animals infected with parasites other than Plasmodium were not used in the trials.

Parasitemia of $P$. mexicanum was estimated by counting the parasites present in 1000 erythrocytes in microscope fields from throughout the blood smear. We also recorded the percent of immature cells among these erythrocytes; malarious lizards typically show elevated numbers of immature blood cells (Schall 1983).

Two $4.9 \times 4.9 \mathrm{~m}$ enclosures were constructed of smooth 
particle board. A cloth skirt glued to the bottom of the walls was held tightly to the ground with a row of rocks. The enclosures were placed in an area where lizards were naturally common and trees provided shade during at least part of the day. The substrate consisted of bare soil, rocks, and grass. Three piles of fence posts and logs were placed into each pen.

Pairs of male lizards, one individual infected with $P$. mexicanum, and one not infected, were matched by snout to vent length (within $0.5 \mathrm{~mm}$, the limit for resolution of body length in a living lizard), tail condition (normal, broken, regenerated), and ventral color pattern. The latter is potentially important because ventral color may function as a social signal between individuals in this species and Ressel (1986) has shown that infected and noninfected fence lizards from the Hopland site differ slightly in average color pattern. A matched pair of male lizards and an adult female lizard were placed in small paper tubes and taken to the pens in the evening. The tubes were placed within the piles of logs and fence posts and opened at one end so that the lizards would we warmed by sunlight the next morning and voluntarily emerge. If an animal had not emerged by midmorning on the first day of observation, or if a lizard remained hidden under rocks on subsequent observation days, it was gently flushed by the observer.

The observer (usually MDD) would arrive at the pens early each morning and sit or stand quietly while watching the lizards' behavior. The pens were watched alternatively, each observation period lasting $30 \mathrm{~min}$. Thus, only one pair of males was observed during any time period. The total time spent watching a pair of lizards was recorded. Because of differing weather conditions from day to day, the total time spent watching a pair of lizards varied. On cloudy or cool days, little or no activity by the lizards was observed. After 2 to 4 days of observation the lizards were removed and new pairs of lizards were put into the pens.

Social behaviors of $S$. occidentalis are usually easy to distinguish (Schall and Sarni 1987). These behaviors include: bobbing by males in which the entire head, trunk, and abdomen were suddenly thrust upward so that the lizard was standing on fully extended limbs; hopping by females in which the animal arched its back, then produced several short hops; chases between males; displacements in which one lizard quickly moved toward a second animal which suddenly left its perching place and moved away (usually between males, but occasionally intersexual); fights in which animals would bite and wrestle each other (always between males); and vertical head or full body shivering shown by both sexes.

The duration of each social interaction was recorded with a stopwatch. Spoken notes were made onto a tape recorder of activity duration and of the number of times each activity occurred during the observation period. Occasionally, other rare kinds of social behaviors were also observed; a detailed record of these events was also spoken onto the tape. The taped notes were later used to produce a permanent written record of the trials. We organized these data into four classes: (1) "Display to Female" = total seconds a male interacted with a female; (2) "Display to Male" = seconds a male displayed toward, chased, or attacked the other male; (3) "Other Display"=seconds a male displayed with no obvious observer lizard present; (4) "Times Chased" = number of times a male was chased or displaced by either the other male or the female.
At the end of each trial we examined the written record to reach agreement on a subjective rating of the outcome. We used the values of the four social interaction classes, outcomes of unusual types of interactions not included in the interaction classes, and intensity of chases and fights. After a winner was decided upon, we would rank the win from weak (1) to strong (3), and the loss symmetrically from weak to strong. Although only one of us knew the identity of the infected male, we almost always independently came to the same rating of the outcome.

\section{Results}

In 17 of the 23 trials, the lizards interacted with each other and appeared to ignore the presence of the observer. Data for the other 6 trials were discarded because the lizards either hid for the entire observation period, spent the entire time seeking to escape, or perched motionlessly for the duration of observations. We assume that the lizards in these trials were influenced by the observer; in several cases the lizards appeared to be watching the observer's movements intensely.

Total observation time was $155.1 \mathrm{~h}$. Observation time for the 17 useful trials lasted from 3.9 to $11.0 \mathrm{~h}(\bar{X}=7.02 \mathrm{~h}$, $\mathrm{SD}=2.19$, total $=119.4 \mathrm{~h})$. Although the time lizards were observed in any social interaction was weakly correlated with total observation time (Spearman correlation, $r_{s}=$ $0.48, P=0.03$ ), most vigorous interaction tended to occur early in the trial, and the observer was usually able to predict the winning male by the end of the first day of observation. Overt social behavior consumed $<1 \%$ of the lizards' time, a result similar to observations on free-ranging animals (Schall and Sarni 1987).

Table 1 presents data for the 17 useful trials. In our judgement of winning males, 12 were noninfected and 5 were infected (Table 1 , Binomial test, $P=0.072$, with expectation of equal number of wins for infected and noninfected males under $H_{o}$ ). Of 10 wins judged "strong," 9 were by noninfected lizards (Binomial test, $P=0.011$ ). "Other Display" time did not differ between infected and noninfected lizards $(P<0.05)$, but "Display to Female," "Display to Male" and total social activity times were all significantly greater for the noninfected Sceloporus (Wilcoxon pairedsample one tailed tests, $P<0.05$ ). Thus, the noninfected males were socially active more often compared to the infected animals and were more likely to dominate social interactions.

We also sought to determine if noninfected lizards actually suppressed social activity by malarious males. Anecdotal evidence suggests they do. Initially in a trial, both lizards would often display, but after one to several chases or displacements, the submissive male would cease any social display behavior. In some cases the submissive male would retreat to a patch of grass, or a crack in a log and remain there for long periods. In one trial, the noninfected lizard escaped briefly from the pen. The infected male immediately moved near the female and began to display toward her. Once the noninfected male was returned to the pen, the infected male remained away from the female for the duration of the trial.

The infected animals used in the trials varied greatly in their Plasmodium parasitemia (over two orders of magnitude, Table 1). If parasite load is important in the outcome of social interactions, then a strong win by an infected ani- 
Table 1. Interaction between western fence lizard males, one infected with the malarial parasite, Plasmodium mexicanum, (coded as I) the other not infected (NI). Given are parasitemia (Para=parasites per 1000 erythrocytes), percent of immature erythrocytes for both animals $(\% \mathrm{iRBC})$, total time of observation (Total Time), seconds display to female $(\rightarrow q)$, second display to other male $\left(\rightarrow \sigma^{*}\right)$, seconds of other display behaviour (Other), times chased by another lizard (Chased), and a rating of the outcome from a weak win (1) to strong win (3), with the infection state of the winner indicated (NI vs. I). Some data for trial 1 were lost in an equipment failure

\begin{tabular}{|c|c|c|c|c|c|c|c|c|c|c|c|c|c|}
\hline Trial & Para & $\begin{array}{l}\text { I } \\
\text { \%iRBC }\end{array}$ & $\begin{array}{l}\text { NI } \\
\% \mathrm{iRBC}\end{array}$ & $\begin{array}{l}\text { Total } \\
\text { Time }\end{array}$ & $\underset{\rightarrow}{I}$ & $\underset{\rightarrow+}{\mathrm{NI}}$ & $\underset{\rightarrow 0}{I}$ & $\underset{\rightarrow 0^{*}}{\mathrm{NI}}$ & $\begin{array}{l}\text { I } \\
\text { Other }\end{array}$ & $\begin{array}{l}\text { NI } \\
\text { Other }\end{array}$ & $\begin{array}{l}\text { I } \\
\text { Chased }\end{array}$ & $\begin{array}{l}\text { NI } \\
\text { Chased }\end{array}$ & Win \\
\hline 1 & 255 & 23 & 1 & 9.92 & & & & & & & 2 & 0 & NI1 \\
\hline 2 & 122 & 19 & 7 & 9.73 & 0 & 478 & 0 & 196 & 5 & 15 & 3 & 0 & NI3 \\
\hline 3 & 209 & 23 & 20 & 5.23 & 0 & 21 & 1 & 197 & 1 & 53 & 8 & 0 & NI3 \\
\hline 4 & 328 & 32 & 20 & 11.05 & 96 & 439 & 0 & 104 & 0 & 179 & 13 & 0 & NI3 \\
\hline 5 & 169 & 20 & 9 & 8.45 & 79 & 30 & 26 & 0 & 13 & 6 & 0 & 0 & 12 \\
\hline 6 & 902 & 32 & 16 & 7.58 & 0 & 29 & 0 & 8 & 0 & 12 & 3 & 0 & NI2 \\
\hline 7 & 117 & 35 & 4 & 5.00 & 0 & 93 & 0 & 6 & 0 & 69 & 2 & 0 & NI3 \\
\hline 8 & 107 & 21 & 13 & 6.90 & 0 & 177 & 0 & 34 & 6 & 76 & 1 & 1 & NI3 \\
\hline 9 & 165 & 28 & 18 & 6.22 & 38 & 14 & 90 & 26 & 42 & 6 & 1 & 3 & $\mathrm{I} 2$ \\
\hline 10 & 20 & 11 & 20 & 4,85 & 0 & 6 & 46 & 18 & 0 & 14 & 0 & 2 & I1 \\
\hline 11 & 9844 & 42 & 23 & 4.50 & 6 & 121 & 35 & 30 & 8 & 18 & 3 & 0 & NI3 \\
\hline 12 & 76 & 25 & 14 & 5.57 & 2 & 0 & 0 & 12 & 6 & 1 & 4 & 0 & NI1 \\
\hline 13 & 412 & 27 & 18 & 6.37 & 9 & 0 & 52 & 3 & 0 & 0 & 0 & 4 & 12 \\
\hline 14 & 2575 & 10 & 5 & 6.37 & 56 & 112 & 19 & 58 & 50 & 57 & 6 & 1 & NI3 \\
\hline 15 & 236 & 23 & 13 & 3.92 & 700 & 5 & 12 & 0 & 102 & 0 & 0 & 1 & I3 \\
\hline 16 & 48 & 23 & 6 & 10.25 & 0 & 77 & 0 & 71 & 0 & 51 & 3 & 1 & NI3 \\
\hline 17 & 1328 & 18 & 1 & 7.50 & 10 & 130 & 8 & 46 & 8 & 16 & 4 & 1 & NI3 \\
\hline
\end{tabular}

mal should be associated with low parasitemia, and a strong loss associated with high parasitemia. Using only data for the infected animal from each trial, the outcome for the infected lizard was ranked from a strong win (rank of 1) to a strong loss (rank of 6). The predicted relationship was observed (Spearman correlation between outcome of trial and median parasitemia for each outcome; $r_{s}=0.77, P<$ $0.05)$.

The primary pathology associated with malarial infection in lizards is an elevated number of immature erythrocytes (Schall 1983); infected animals in the trials had significantly higher immature cell counts (Table 1, Mann-Whitney test, $P<0.001$ ). However, parsitemia and percent of immature red blood cells were not correlated (Spearman correlation, $P<0.10$ ), a result usually seen in lizard malria infections (Schall 1983). Percent immature erythrocytes was not correlated with outcome of trials, ranking infected animals from a strong win to a strong loss as above (Spearman correlation, $P>0.05$ ).

Although our experiment was designed to evaluate male behavior, we also made observations on the females' response to male activities. Females often appeared to be watching male displays intensely. Also, surprisingly, females occasionally actually left their perching site to approach the male that had lost an agonistic encounter and remained very close to the subordinate male. This initiated an approach and further attack on the subordinate male by the apparently dominant lizard. In two trials, this sequence of events happened repeatedly.

\section{Discussion}

When infected with malaria, Sceloporus occidentalis suffers a series of important pathological effects. Immature erythrocytes become more abundant, hemoglobin content of the blood drops, and aerobically supported activity declines (Schall et al. 1982; Schall 1983). Although fence lizards in the wild seldom engage in running locomotion that lasts for more than a few seconds, male lizards occasionally spend several minutes in intense social interactions with other males and females (Schall and Sarni 1987). This kind of social interaction might well require rapid mobilization of oxygen to tissues, which appears to be hindered by Plasmodium parasitism. Thus, we predicted that infection with malaria might interfere with a male lizard's ability to maintain a territory or court mates.

We matched lizards in the trials by size, approximate body mass, color, and tail condition. None of the infected lizards was conspicuously sick; all were active and alert while being processed in the laboratory. Infected lizards seemed able to court females, provided a challenger was not present. Yet, when matched against a noninfected lizard, malarious $S$. occidentalis generally displayed less often to both the challenging male and to the female, and more often lost the encounter. The few infected lizards that appeared to win the encounter were generally those with low malaria parasitemia. Thus, we conclude that malarial infection reduces the ability of a male $S$. occidentalis to successfully court females if a noninfected male is present.

If the reduction in social interaction by malarious males is a direct result of their reduced hemoglobin levels and aerobic abilities, as suggested earlier (Schall and Sarni 1987), then we expected malarious males initially to engage in vigorous interaction with competing males unitl exhaustion required their retreat. However, infected lizards generally abandoned any effort to court the female or demonstrate agonism toward the other male after only a short period of social interaction. These results suggest that malarious males somehow assess in subtle ways their relative ability to succeed in male-male interaction.

Demonstrating female choice in courtship is notoriously difficult (Halliday 1983). Females in our trials appeared to observe male activities, and even to initiate male-male conflict behavior. Similar behavior by females occurs under 
natural circumstances as well (Schall and P. Houle unpublished work). Intense social interaction between males can continue over several days in nature, while one or more females perch on elevated sites apparently observing the interactions. Thus, any reduction in a male's ability to fend off attacks by other males seems critical in its ability ultimately to produce offspring.

Lizards have proven to be important models in tests of sexual selection theory (for example, Hicks and Trivers 1983), but the possible confounding role of parasites in field and laboratory studies of lizard reproductive behavior generally has been ignored. Most lizard populations that have been surveyed have proven to be hosts for a wide array of potentially pathogenic parasites (Telford 1984). The impact of malaria on mating success of male Sceloporus occidentalis suggests parasites may play an important role in reproductive behavior of individuals in many other lizard populations.

Acknowledgements. We thank A.H. Murphy and the staff of the Hopland Field Station for their cooperation and assistance during our stay there. P. Houle, P. Manley, R. Wilson, and S. Ressel offered valuable comments. T. Hanson assisted with the literature search. The research was funded by US NSF grant BSR-8516627 to JJS.

\section{References}

$\rightarrow$ Ayala SC (1971) Sporogony and experimental transmission of Plasmodium mexicanum. J Parasitol 57:598-602

Bateson P (1983) Mate Choice. Cambridge Univ. Press, Cambridge

Baudoin M (1975) Host castration as a parasitic strategy. Evolution 29:335-352

Blum MS, Blum NA (1979) Sexual Selection and Reproductive Competition in Insects. Academic Press, New York

$\rightarrow$ Bromwich CR, Schall JJ (1986) Infection dynamics of Plasmodium mexicanum a malarial parasite of lizards. Ecology 67: $1227-1235$

$\rightarrow$ Freeland WJ (1976) Pathogens and the evolution of primate sociality. Biotropica 8:12-24

$\rightarrow$ Freeland WJ (1981) Parasitism and behavioral dominance among male mice. Science $213: 461-462$

Halliday RR (1983) The study of mate choice. In: Bateson P (ed) Mate Choice. Cambridge Univ. Press, Cambridge, pp 3-32

$\rightarrow$ Hamilton WD, Zuk M (1982) Heritable true fitness and bright colors: A role for parasites? Science 218:384-387

Hausfater G, Watson DF (1976) Social and reproductive correlates of parasite ova emissions by baboons. Nature 262:688-689

Hicks R, Trivers R (1983) the social behavior of Anolis valencienni. In: Rhodin A, Miyata K (eds) Advances in Herpetology and Evolutionary Biology. Museum of Comparative Zoology, Cambridge, MA, pp 570-595

$\rightarrow$ Kuris AM (1974) Trophic interactions: similarity of parasitic castrators to parasitoids. Q Rev Biology 49:129-148

Rau ME (1983) Establishment and maintenance of behavioural dominance in male mice infected with Trichinella spiralis. Parasitology 86:319-322

Ressel SJ (1986) Sexual color dimorphisms, sexual selection, and malarial parsitism in the western fence lizard, Sceloporus occidentalis. MS thesis, University of Vermont, Burlington

Schall JJ (1983) Lizard malaria: parasite-host ecology. In: Huey RB, Pianka ER, Schoener TW (eds), Lizard Ecology; Studies of a Model ORganism. Harvard Univ. Press, Cambridge, pp 84-100

$\rightarrow$ Schall JJ, Sarni GA (1987) Malarial parasitism and the behavior of the lizard, Sceloporus occidentalis. Copeia 1987:84-93

$\rightarrow$ Schall JJ, Bennett AF, Putnam RW (1982) Lizards infected with malaria: physiological and behavioral consequences. Science 217:1057-1059

Telford SR (1984) Haemoparasites of reptiles. Hoff GL, Frye FL, Jacobson ER (eds), Diseases of Amphibians and Reptiles. Plenum Publ Corp, New York, pp 385-517

Received January 15, 1987 